\title{
THE PATTERN OF MEDICAL MORTALITIES IN A SPECIALIST HOSPITAL IN NORTH-CENTRAL NIGERIA.
}

\author{
${ }^{1}$ Joseph O. Fadare and ${ }^{2}$ A.O. Afolabi
}

1. Department of Medicine, Kogi State Specialist Hospital, Lokoja, Nigeria

2. Department of Surgery, Kogi State Specialist Hospital, Lokoja, Nigeria

\author{
Correspondence: \\ Dr. Joseph O. Fadare \\ Department of Medicine, \\ Kogi State Specialist Hospital, \\ Lokoja, Nigeria \\ Email: jofadare@gmail.com
}

\begin{abstract}
Background: Review of causes of morbidity and mortality in health care facilities is an important exercise which gives a picture of the prevailing disease pattern in the particular community and at the same time looks out for any change in the disease pattern over time. This exercise is a necessary component for planning of the health care needs of the community.

Objective: To determine the mortality pattern on the medical wards of the Kogi State Specialist Hospital, a tertiary center located in Lokoja, North-Central Nigeria.

Methods: A retrospective review of medical records of all patients admitted to the medical wards of the hospital over a period of 18 months (December 2008 - May 2010) was carried out. The information recorded from these sources included the age and gender, diagnosis / cause of death and the duration of admission.

Results: A total of six hundred and eighty-four patients were admitted during the period being studied with a predominance of female patients (Female: Male Ratio $=1.07)$. There were seventy-six deaths $\mathbf{( 1 1 . 1 \% )}$ during the period in question with HIV and related complications accounting for most recorded mortality $(32.9 \%)$ closely followed by non-communicable cardiovascular conditions (hypertension, heart failure and CVD) $-28.9 \%$.

Conclusion: This study clearly shows that HIV infection and its complications remains the leading cause of death despite the advent of HAART. Clearly there is a need to revisit the strategies of HIV prevention and control. Also there is an urgent need to focus on the prevention and treatment of non-communicable diseases like hypertension and diabetes.
\end{abstract}

Keywords: Mortality pattern, causes, medical wards, Nigeria

\section{INTRODUCTION}

The review of causes of morbidity and mortality in health care facilities is an important exercise with farreaching implications. This form of clinical audit gives a picture of the prevailing disease pattern in the particular community and at the same time looks out for any change in the disease pattern over time. It a well known fact that the lifestyle and habits of most people living in developing countries like Nigeria is being influenced tremendously by the that of the western world ${ }^{1}$. This obviously has its own effect on the health status of the population of these nations leading to a change in the disease pattern seen in these nations. The information provided by this kind of review plays an important role in future planning and strategizing for better service provision in the health care sector ${ }^{2}$. It also highlights the particular areas where the government and various non-governmental organizations have to prioritize as regards health care delivery to the community.

Studies carried out in Nigeria in the pre-HIV and early post-discovery era ${ }^{3,4}$ revealed non-HIV infections and cardiovascular conditions as the main causes of medical mortality, it is important to investigate the current trend in our environment especially in this era of HIV/AIDS. For the purposes of this study, it will be practical to view the HIV/AIDS period in two phases: the pre-ARV, and the post- ARV. While studies done in the pre-ARV period showed that HIV/AIDS or its related conditions were the main causes of 


\begin{tabular}{lllll}
\hline Ward & Mean age (years) & No of admissions & No of deaths & Duration of admission (days) \\
\hline Male & $52.5 \pm 19.1$ & $330(48.2 \%)$ & $42(12.7 \%)$ & $5.9 \pm 5.8$ \\
Female & $51.6 \pm 19.2$ & $354(51.8 \%)$ & $34(9.6 \%)$ & $5.7 \pm 6.6$ \\
Total & $52.1 \pm 19.6$ & 684 & $76(11.1 \%)$ & $5.8 \pm 6.2$ \\
\hline
\end{tabular}

Table 1: No. of admissions and mortality

morbidity and mortality in the medical wards ${ }^{5,6}$, there is a need to assess the trend especially now ARVs are now more accessible to patients needing them in developing countries at little or no cost.

Global projections of mortality and burden of disease up to 2030 have indicated a significant shift from infectious/communicable to non-communicable diseases worldwide and this transition is expected to affect developing countries like Nigeria ${ }^{7}$. The objective of this study was to investigate the causes of mortality on the medical wards of a specialist hospital in Lokoja, north-central Nigeria and to observe whether the trends discussed earlier exist in our environment.

\section{METHODS}

A retrospective review of medical records of all patients admitted to the medical wards of the Kogi State Specialist Hospital, Lokoja, North-central Nigeria was carried out. Lokoja, located about 200 kilometres from Abuja (the Federal Capital), is a major transit town connecting the Northern and Southern parts of Nigeria. It is also a major inland river port and the meeting point of the rivers Niger and Benue. This centre is one of two medical facilities rendering tertiary level health care services for the people of Lokoja, capital of Kogi State and its environs. The facility is an 80-bed hospital, with the medical wards accounting for thirty-two. It also provides in-patient and out-

\begin{tabular}{ll}
\hline Diagnosis & Frequency \\
\hline Retroviral disease and associated complications & $25(32.9 \%)$ \\
Severe hypertension/encephalopathy & $8(10.5 \%)$ \\
Congestive cardiac failure & $3(3.9 \%)$ \\
Cerebro-vascular accident & $11(14.5 \%)$ \\
Chronic liver disease & $5(6.8 \%)$ \\
Diabetes mellitus & $4(5.3 \%)$ \\
Septicaemia & $4(5.3 \%)$ \\
Acute coronary syndrome & $2(2.6 \%)$ \\
Chronic renal failure & $2(2.6 \%)$ \\
Lobar pneumonia & $2(2.6 \%)$ \\
Tetanus & $1(1.3 \%)$ \\
Acute viral hepatitis & $1(1.3 \%)$ \\
Snake bite & $1(1.3 \%)$ \\
Dementia & $1(1.3 \%)$ \\
Bronchial Asthma & $1(1.3 \%)$ \\
Sickle cell anaemia (Vaso-occlusive crisis) & $1(1.3 \%)$ \\
Cerebrospinal meningitis & $1(1.3 \%)$ \\
Ca Prostate & $1(1.3 \%)$ \\
Malignant pleural effusion & $1(1.3 \%)$ \\
\hline
\end{tabular}

Table 2: Causes of mortality 
patient care with about twenty specialists in various fields of medicine: internal medicine, paediatrics, surgery, obstetrics and gynaecology, haematology and histopathology. In addition to providing services in the above mentioned fields, the hospital also has a fully functional HIV/ARV clinic which is supported by the federal government of Nigeria and some foreign developmental partners which has been operational in the last three years. The review included all cases admitted to the medical wards of the hospital from December 2008 till the end of May 2010 and the records used for this study are the admission and discharge register, patients' case notes and copies of death certificates. The information recorded from these sources included the age and gender, diagnosis / cause of death and the duration of admission. The data was entered and analyzed using SPSS version 12.

\section{RESULTS}

A total of six hundred and eighty-four patients were admitted during the period being studied with a predominance of female patients (Female: Male Ratio $=1.07)$. The mean age of the patients that died during this period was $52.1 \pm 19.6$ years. The mean duration of admission was $5.8 \pm 6.2$ days, however more than a third of all mortalities took place within the first twenty-four hours of admission. The breakdown of admissions and mortality are captured in Table 1.

Regarding the causes of mortality, HIV infection and its related complications was the major culprit $(32.9 \%)$ followed by cerebro-vascular accident (14.5\%). The details of the causes of mortality in this study are shown in Table 2:

The $\mathrm{M}: \mathrm{F}$ ratio of patients dying from HIV/AIDS from this study was about 1.08:1 (13:12), while the mean age at death was 36.5 years. It was interesting to note that more female patients $(64 \%)$ died from cerebro-vascular diseases than their male counterparts. The mean age at death for this subgroup of female patients was 64.1 years. The analysis of gender distribution among the major causes of mortality is shown in Table 3 below:

\begin{tabular}{lcc}
\hline D isease & M ale (N) & Fem ale (N) \\
\hline H IV / AID S & 13 & 12 \\
Stroke & 4 & 7 \\
H ypertension & 5 & 3 \\
\hline
\end{tabular}

Table 3: Gender distribution of cause of mortality

\section{DISCUSSION}

The mean age recorded in this study is at variance from results similar studies from developed countries with mean age at death of 76.5 and 79 years respectively ${ }^{9}$ ${ }^{10}$. This significant difference can be explained by the level of economic development of these nations making access to quality health care services the norm. The mortality rate of $11.1 \%$ from our study was lower than $25.3 \%$ found in a larger study from the northwestern part of Nigeria ${ }^{2}$ and higher than $3.4 \%$ found in the European study mentioned above 9 . This difference could be due in part to the larger number of cases reviewed in the former study and a variation in the health seeking behavior of people from different regions of Nigeria which may be related to certain socio-cultural beliefs. The relatively low level of mortality recorded in the European study can be explained by the level of economic development of the countries translating into high standard of living and highly efficient health care services. About a third of the deaths occurred within twenty-four hours of admission during the period under review, a finding at variance with an earlier cited Nigerian study with over $83 \%$ mortality within the first 24 hours $^{2}$. This significant number of deaths occurring shortly after admission could be explained by the severity or advanced stage of the disease condition. In addition, most patients present late to the hospital and this contribute to the very poor outcome. Some reasons for the late presentation include: a poor referral system whereby many private hospitals hold on to patients for too long, the influence of traditional medicine practitioners, transportation problems and economic factors.

One of the reasons for mortality review is to observe changing patterns in the cause of mortality over a particular period of time. From our findings, HIV/ AIDS still remained the major cause of mortality followed by conditions of cardiovascular origin mainly hypertension and congestive cardiac failure. The study site and indeed Kogi state has a higher than national average HIV prevalence of about $5.8 \%{ }^{8}$ which could be explained by earlier mentioned peculiar location of the town. However, this outcome is still very disturbing from a centre with a fully functional ARV clinic for about three years. Some of the possible responsible factors are: late diagnosis of the infection, poor drug adherence and possible drug resistance and societal attitude to the disease. Studies carried out in the pre-HIV era in some African countries ${ }^{4,5}$, revealed non-HIV infectious diseases, stroke and liver disease as the major causes of mortality. Previously cited studies from other Europe show that stroke, cardiovascular diseases and neoplasm are the major cause of mortality on the medical wards ${ }^{9,10}$. The result of our study suggests that neoplasm is a very rare 
cause of mortality in our environment; this conclusion however may not be totally true. This is because of lack of equipment for proper diagnosis and management of these conditions in the setting of a developing country like Nigeria. There is also the factor of health seeking behavior of the populace especially as some people still visit non-orthodox health care practitioners due to access problems or personal beliefs.

Non-communicable conditions like hypertension, congestive heart failure, cerebrovascular accident and acute coronary syndrome contributed a very significant part of the total mortality in our study. Odia et al in their study reported that stroke was responsible for $15.9 \%$ of deaths on the medical wards ${ }^{11}$ while hypertensive conditions accounted for $16.1 \%$ of medical mortality in another report from Benin City, South-south Nigeria ${ }^{12}$. The preponderance of females among deaths secondary to stroke in our study could be explained by the fact that most of them were postmenopausal and have subsequently lost their "hormonal protection". This increase in noncommunicable diseases is the expected trend for the future especially because of the "westernization" of our diet and lifestyle in this part of the world. There is a need for government to put in place public enlightenment strategies in addition to adequate diagnostic and management protocols to combat this menace. Indeed some workers have made projections regarding the burden of disease in the next few decades 7,13 and findings from this study tend to corroborate their projections. A very important question that is raised by this study is whether the availability of HAART in our establishment over the last three years has affected the prognosis of HIV/AIDS among infected individuals. Several studies from other parts of the world have shown that hospital HIV-related mortality is reducing especially since the inception of HAART $^{14,15}$. Results from a similar study in Nigeria however show that mortality due to HIV-related conditions continues to increase ${ }^{16}$. Some reasons that can be adduced for this worrisome trend include delayed diagnosis, issues of adherence, lack of access to HAART, late presentation at the hospital and lack of diagnostic aids for detection of opportunistic infections. More emphasis should be placed on continued public enlightenment and education about HIV/AIDS as a disease entity, its prevention and management, a strategy that has been relegated to the background since the introduction of HAART in our environment. Additional efforts at primary prevention and prompt treatment of non-communicable diseases should also be re-enforced.

\section{LIMITATIONS}

The main limitation of this study was the difficulty in obtaining autopsies of the deceased patients. This was mainly because of religious and other socio-cultural beliefs of the host community which had to be respected. Because of this, most of our diagnoses were clinical mostly supported by laboratory and radiological findings.

\section{CONCLUSION}

The findings from our study show a troubling trend an increase in mortality due to both non-communicable and HIV-related conditions despite the introduction of HAART. There is a need to revisit the strategies for HIV/AIDS control and treatment in our environment. Approaches towards the control and prevention of non-communicable disease conditions like hypertension and diabetes also deserve to be strengthened.

\section{REFERENCES}

1. Chukwuma C. Sr, Tuomilehto J. The 'thrifty' hypotheses: clinical and epidemiological significance for non-insulin-dependent diabetes mellitus and cardiovascular disease risk factors. J Cardiovasc Risk. 1998; 5:11-23.

2. Sani MU, Mohammed AZ, Bapp A, Borodo MM. A three-year review of mortality patterns in the medical wards of Aminu Kano Teaching Hospital, Kano, Nigeria. Niger Postgrad Med J. 2007; 14 : 347-351.

3. Ogun SA, Adelowo OO, Familoni OB, Jaiyesimi AE, Fakoya EA. Pattern and outcome of medical admissions at the Ogun State University Teaching Hospital, Sagamu — a three year review. West Afr J Med. 2000;19: 304-308

4. Adetuyibi A, Akisanya JB, Onadeko BO. Analysis of the causes of death on the medical wards of the University College Hospital, Ibadan over a 14year period (1960-1973). Trans R Soc Trop Med Hyg. 1976;70:466-473

5. Yohannes AG, Fekade D. Morbidity and mortality of adult patients with HIV/AIDS at Tikur Anbessa Teaching Hospital, Addis Ababa, Ethiopia. Ethiop Med J. 2003; 41:131-140

6. Harries AD, Mvula B. The changing pattern of mortality in an African medical ward. Trop Geogr Med. 1995; 47:171-174.

7. Mathers CD, Loncar D. Projections of global mortality and burden of disease from 2002 to 2030. PLoS Med. 2006; 3:e442

8. Federal Ministry of Health (FmoH), 2003. Technical Report 2003 National HIV Seroprevalence Sentinel Survey. Federal Ministry of Health 
9. Papadopoulos IN, Papaefthymiou M, Roumeliotis L, Panagopoulos VG, Stefanidou A,Kostaki A. Status and perspectives of hospital mortality in a public urban Hellenic hospital, based on a five-year review. BMC Public Health. 2008; 23:8-28.

10. Rayego Rodríguez J, Rodríguez-Vidigal FF, Mayoral Martín L, Alvarez-Oliva A, Najarro Díez F. Hospital mortality in the Internal Medicine Services of a first level center] An Med Interna. 2006; 23:406-410.

11. Odia OJ. Mortality patterns in the medical wards of a Nigerian Teaching Hospital. Orient J Med 1992; 4:96-101.

12. Ukoh VA. Admission of hypertensive patients at the University of Benin Teaching Hospital, Nigeria. East Afr Med J. 2007 ;84:329-335

13. Lopez AD, Mathers CD. Measuring the global burden of disease and epidemiological transitions: 2002-2030. Ann Trop Med Parasitol. 2006; 100:481-499.
14. Hooshyar D, Hanson DL, Wolfe M, Selik RM, Buskin SE, McNaghten AD. Trends in perimortal conditions and mortality rates among HIV-infected patients. AIDS. 2007 ;21:2093-2100

15. Palella FJ Jr, Baker RK, Moorman AC, Chmiel JS, Wood KC, Brooks JT, Holmberg SD; HIV Outpatient Study Investigators Mortality in the highly active antiretroviral therapy era: changing causes of death and disease in the HIV outpatient study. J Acquir Immune Defic Syndr. 2006; 43:2734.

16. Sani MU, Mohammed AZ, Adamu B, Yusuf SM, Samaila AA, Borodo MM. AIDS mortality in a tertiary health institution: A four-year review. J Natl Med Assoc. 2006; 98:862-866. 